\title{
Task Division within the Prefrontal Cortex: Distinct Neuron Populations Selectively Control Different Aspects of Aggressive Behavior via the Hypothalamus
}

\author{
Laszlo Biro, ${ }^{1,3}$ @Eszter Sipos, ${ }^{1}{ }^{\circledR}$ Biborka Bruzsik,,${ }^{1,3}$ @Imre Farkas, ${ }^{2}$ Dora Zelena, ${ }^{1}$ Diana Balazsfi, ${ }^{1}$ Mate Toth, ${ }^{1 *}$ \\ and Jozsef Haller ${ }^{1,4 *}$ \\ ${ }^{1}$ Department of Behavioral Neuroscience, ${ }^{2}$ Laboratory of Endocrine Neurobiology, Institute of Experimental Medicine, H-1450, Budapest, Hungary, ${ }^{3}$ Janos \\ Szentagothai School of Neurosciences, Semmelweis University, 1085, Budapest, Hungary, and ${ }^{4}$ Faculty of Law Enforcement, National University of Public \\ Service, 1083, Budapest, Hungary
}

An important question in behavioral neurobiology is how particular neuron populations and pathways mediate the overall roles of brain structures. Here we investigated this issue by studying the medial prefrontal cortex (mPFC), an established locus of inhibitory control of aggression. We established in male rats that dominantly distinct mPFC neuron populations project to and produce dense fiber networks with glutamate release sites in the mediobasal hypothalamus $(\mathrm{MBH})$ and lateral hypothalamus (LH; i.e., two executory centers of species-specific and violent bites, respectively). Optogenetic stimulation of mPFC terminals in MBH distinctively increased bite counts in resident/intruder conflicts, whereas the stimulation of similar terminals in LH specifically resulted in violent bites. No other behaviors were affected by stimulations. These findings show that the mPFC controls aggressiveness by behaviorally dedicated neuron populations and pathways, the roles of which may be opposite to those observed in experiments where the role of the whole mPFC (or of its major parts) has been investigated. Overall, our findings suggest that the mPFC organizes into working units that fulfill specific aspects of its wide-ranging roles.

Key words: aggression; hypothalamus; optogenetics; prefrontal cortex; rats; social behavior

Significance Statement

Aggression control is associated with many cognitive and emotional aspects processed by the prefrontal cortex (PFC). However, how the prefrontal cortex influences quantitative and qualitative aspects of aggressive behavior remains unclear. We demonstrated that dominantly distinct PFC neuron populations project to the mediobasal hypothalamus (MBH) and the lateral hypothalamus (LH; i.e., two executory centers of species-specific and violent bites, respectively). Stimulation of mPFC fibers in MBH distinctively increased bite counts during fighting, whereas stimulation of similar terminals in LH specifically resulted in violent bites. Overall, our results suggest a direct prefrontal control over the hypothalamus, which is involved in the modulation of quantitative and qualitative aspects of aggressive behavior through distinct prefrontohypothalamic projections.

\section{Introduction}

The prefrontal cortex (PFC) is the main locus of control for higher cognitive and emotional processes and goal directed be-

\footnotetext{
Received Nov. 13, 2017; revised Feb. 9, 2018; accepted Feb. $17,2018$.

Author contributions: L.B., M.T., and J.H. designed research; L.B., E.S., B.B., I.F., D.Z., D.B., M.T., and J.H. performed research; L.B., E.S., B.B., I.F., M.T., and J.H. analyzed data; L.B., M.T., and J.H. wrote the paper.

Funding for this study was provided by National Research, Development and Innovation Office Grants 112907 and 125390; Research workshop "Criminal Psychology" of the KÖFOP-2.1.2-VEKOP-15-2016-00001 project and grant ERC-2011-ADG-294313; and the Bolyai Janos Research Fellowship to M.T. The authors thank Dr. Tamás Fuzesi (Department of Physiology and Pharmacology, Hotchkiss Brain Institute, University of Calgary, Calgary, AB, Canada) and Dr. Csaba Fekete (Laboratory of Integrative Neuroendocrinology, Institute of Experimental Medicine, Hungarian Academy of Sciences, Budapest, Hungary) for their invaluable help and advice in designing the electrophysiological experiments; and Dr. Demeter Kornel for his help in creating the 3D images.

${ }^{*}$ M.T. and J.H. contributed equally to this work.
}

haviors (Ray and Zald, 2012; Pessoa, 2015). However, the manner in which the PFC achieves these wide-ranging functions remains largely unknown. Deconstructing global roles into specific roles by subdividing the area (Smith and Jonides, 1999; Van De Werd et al., 2010) is only a partial solution to the problem because even such subdivisions have a multitude of output areas (Ongür and Price, 2000; Heidbreder and Groenewegen, 2003). Closer insights may be achieved by optogenetics, which enables the stimulation

\section{The authors declare no competing financial interests.}

Correspondence should be addressed to Dr. Jozsef Haller, Institute of Experimental Medicine, Department of Behavioral Neuroscience, P.0. Box 67, H-1450, Budapest, Hungary. E-mail: haller.jozsef@koki.mta.hu. D0I:10.1523/JNEUROSCI.3234-17.2018

Copyright $\odot 2018$ the authors $\quad 0270-6474 / 18 / 384065-11 \$ 15.00 / 0$ 
of axon terminals in target areas. Combined with the identification of projection neurons, this technique enables the understanding of the role of specific neuron populations rather than of subregions that comprise heterogeneous neuron populations (Yizhar et al., 2011; Tye and Deisseroth, 2012).

Here we used optogenetics to understand the role of the medial PFC (mPFC) in aggression, for which this brain area is a critical control site (Siegel et al., 2007). We focused on the pathways that connect the mPFC to two hypothalamic centers that control biting attacks [i.e., the mediobasal hypothalamus (MBH) and lateral hypothalamus (LH); Sesack et al., 1989; Toth et al., 2010]. The rat MBH or hypothalamic attack area is an electrophysiologically defined region, which is located ventrally and medially to the fornix and comprises the posterior parts of the anterior hypothalamus, the tuber cinereum area, and the nucleus of ventrolateral parts of the ventromedial hypothalamus $(\mathrm{VMHvl})$. The electric stimulation of this area elicits biting attacks on conspecifics (e.g., partner rats placed in the test cage; Kruk et al., 1990). Hypothalamic areas with similar functions were found in cats (mediobasal hypothalamus), mice (VMHvl), marmosets (ventromedial hypothalamus), and humans (posteromedial hypothalamus; Siegel et al., 1999; Lin et al., 2011; Haller, 2013; Lee et al., 2014). By contrast, the electric stimulation of the $\mathrm{LH}$, which is located laterally to the fornix, evokes predatory attacks in rats (e.g., the killing of mice and frogs; Vergnes and Karli, 1969; Bandler, 1970). The electrical stimulation of the lateral hypothalamus also elicits predatory attacks in cats (rat killing; Siegel et al., 1999). More recently, the lateral hypothalamus was implicated in attacks delivered on conspecifics, particularly in models of abnormal aggression, where rats are exposed to etiological factors of aggression-related psychopathologies (Haller and Kruk, 2006; Tulogdi et al., 2010; Miczek et al., 2013). In such models, biting attacks were primarily aimed at vulnerable body parts of opponents (head, throat, and belly), and, in addition, the social signaling of attack intentions was considerably reduced (Haller et al., 2001; Tóth et al., 2008). In the context of resident/ intruder (RI) tests, these behaviors disregard species-typical rules; therefore, attacks on vulnerable targets and those that were not signaled socially were considered abnormal or violent, two terms used interchangeably in this article. Such attacks, in contrast to speciestypical ones were associated with marked increases in LH activation; moreover, there was a significant interaction between the frequency of abnormal attacks and LH activation (Tulogdi et al., 2010; Toth et al., 2012).

Here we investigated the anatomical, physiological, and behavioral characteristics of the mPFC-LH and mPFC-MBH projections by using retrograde tracing, immunohistochemistry, slice electrophysiology, in vivo axonal photostimulation, and behavioral techniques. From a broader perspective, the roles played by the two pathways may shed light on how the overall roles of the $\mathrm{mPFC}$ are achieved by its functional units, a phenomenon that remains largely unknown.

\section{Materials and Methods}

Animals

We studied adult male Wistar rats (Charles River Laboratories), which were group housed until undergoing surgery, and thereafter were housed individually until the end of the experiment. Food and water were available ad libitum, while temperature and relative humidity were kept at $22 \pm 2^{\circ} \mathrm{C}$ and $60 \pm 10 \%$, respectively. Rats were maintained in a reverse $12 \mathrm{~h}$ light/dark cycle with lights off at 8:00 A.M. No rat was handled except for regular cage cleaning. The opponents used in aggressive encounters came from the same source and weighed $\sim 300 \mathrm{~g}$. These rats were group housed during the whole experiment and were maintained under similar conditions. The experiments were performed in accordance with the European Communities Council Directive of 2010 (2010/ $63 / \mathrm{EU})$ and were reviewed and approved by the Animal Welfare Committee of the Institute of Experimental Medicine.

\section{Experimental designs and procedures}

Retrograde tracing (Experiment 1). We investigated the $\mathrm{mPFC}-\mathrm{MBH}$ and mPFC-LH pathways from the two hypothalamic sites by using cholera toxin $\beta$ subunit (CTB) and Fluorogold (FG), respectively, as retrograde tracers. All surgeries were performed in a stereotaxic frame (Kopf Instruments) under deep ketamine (50 mg/kg; Medicus Partner), xylazine (20 $\mathrm{mg} / \mathrm{kg}$; Medicus Partner), and pipolphen $(0.2 \mathrm{ml} / \mathrm{kg}$; Egis $)$ anesthesia. After a midline incision, a hand drill was used to expose the brain surface above the target site. Retrograde tracers and viral vectors were microinjected through a glass pipette (the diameter of the tip was $20-30 \mu \mathrm{m}$ ) by using a MicroSyringe Pump Controller System (World Precision Instruments). In Experiment 1, we injected either $50 \mathrm{nl}$ of $1 \%$ CTB into the $\mathrm{MBH}$ [anteroposterior (AP), $-1.6 \mathrm{~mm}$; ML, $-1.2 \mathrm{~mm}$; DV, $-9.2 \mathrm{~mm}$; CTB, List Biological Laboratories] or $20 \mathrm{nl}$ of $2 \%$ Fluorogold into the $\mathrm{LH}$ (AP, $-2,3 \mathrm{~mm}$; ML, $-2,1 \mathrm{~mm}$; DV , $-8,5 \mathrm{~mm}$; FG, Fluorochrome). In this experiment, rats did not undergo behavioral testing. Two weeks after the injections, rats were anesthetized and transcardially perfused with $150 \mathrm{ml}$ of ice-cold saline, followed by $300 \mathrm{ml}$ of $4 \%$ paraformaldehyde in $0.1 \mathrm{~m}$ PBS, pH 7.4. Brains were removed and postfixed in the same fixative overnight, and cryoprotected in $30 \%$ sucrose in PBS at $4^{\circ} \mathrm{C}$ for $2 \mathrm{~d}$ before sectioning (30 $\mu \mathrm{m}$ coronal sections) on a sliding microtome. Only animals with injection sites limited to the $\mathrm{MBH}(n=4), \mathrm{LH}(n=4)$, or both in the case of double injection $(n=3)$ were included in the analysis. CTB-positive and FG-positive cell bodies in the infralimbic cortex (IL) and prelimbic cortex (PrL) were labeled by immunohistochemical methods as follows. A previously described immunohistochemical protocol was used (Biro et al., 2017) with slight modifications as indicated in Table 1. Briefly, after several rinses in PBS, sections ( $90 \mu \mathrm{m}$ apart) were incubated in PBS containing 0.3\% Triton X-100 (Sigma-Aldrich) and $0.3 \%$ $\mathrm{H}_{2} \mathrm{O}_{2}$ for 30 min. Then, after several washes in PBS, sections were incubated in PBS containing either 5\% normal donkey serum or 10\% normal goat serum for $90 \mathrm{~min}$, which was followed by incubation in primary antibody solution (in PBS containing $2 \%$ normal donkey serum) for $48-72 \mathrm{~h}$ at $4^{\circ} \mathrm{C}$. Primary antibodies were detected by either biotin- or fluorescent-conjugated IgG antibodies (1:200-1000; Jackson ImmunoResearch Europe) using a 1-2 h incubation time. All specific primary and secondary antibodies and their applications are summarized in Table 1. In case of biotin-conjugated antibodies, labeling was amplified by avidin-biotin complex (1:1000; Vector Laboratories) by incubation for $1 \mathrm{~h}$ at room temperature. The peroxidase reaction was developed in the presence of diaminobenzidine tetrahydrochloride $(0.2 \mathrm{mg} / \mathrm{ml})$, nickelammonium sulfate $(0.1 \%)$, and hydrogen peroxide $(0.003 \%)$ dissolved in Tris buffer. Sections were mounted onto gelatin-coated slides, dehydrated, and coverslipped with DPX Mountant (Sigma-Aldrich). Regions of interest were digitalized by an Olympus DP70 Light Microscope and CCD camera system at $60-250 \times$ magnification, and analyzed by an experimenter blind to treatments. Sections labeled with fluorescentconjugated antibodies were mounted on glass slides and coverslipped using Mowiol4-88 fluorescent mounting medium and analyzed using C2 Confocal Laser-Scanning Microscope (Nikon Europe). Two-dimensional overview images (tiles) of mPFC were acquired by 488,561 , and $642 \mathrm{~nm}$ lasers. Images were taken of three sections (at $+3.7,+3.2$, and +2.7 levels from bregma). For the FG/CTB coexpression quantification, single-labeled and double-labeled neurons were counted manually using NIS Elements Software (Nikon Europe; RRID:SCR_014329), while NeuN-positive cell counting was performed using ImageJ Software (version 1.41; National Institutes of Health; RRID:SCR_003070).

Characterization of $m P F C$ efferents at the level of $M B H$ and $L H$ (Experiment 2). Here we investigated the arborization of $\mathrm{MPFC}$ neurons in the $\mathrm{LH}$ and $\mathrm{MBH}$, and checked the presence of axon terminals in these hypothalamic fields. The study was performed in those rats, which were used in the behavioral experiments presented below. As anterograde tracers, we used adeno-associated virus (AAV)-mediated gene transfer carrying the gene for channelrhodopsin-2 (ChR2) fused to enhanced 
Table 1. Details of the immunohistochemical reagents used in the study

\begin{tabular}{|c|c|c|c|}
\hline Antigen targeted & Primary antibody & Secondary antibody & Tertiary antibody/amplification \\
\hline NeuN & $\begin{array}{l}\text { Mouse monoclonal (1:5000; catalog \#MAB377, } \\
\text { Merck Millipore; RRID:AB_2298772) }\end{array}$ & Alexa Fluor 647-conjugated donkey lgG (1:200) & None \\
\hline СТВ & $\begin{array}{l}\text { Goat polyclonal (1:5000; catalog \#703, List } \\
\text { Biological Laboratories; RRID:AB_2314252) }\end{array}$ & $\begin{array}{l}\text { Biotin/Alexa Fluor 594-conjugated donkey lgG } \\
(1: 1000 / 1: 200)\end{array}$ & $A B C /$ none \\
\hline FG & $\begin{array}{l}\text { Rabbit polyclonal (1:10,000; Fluorochrome; } \\
\text { RRID:AB_2314408) }\end{array}$ & Biotin-conjugated donkey IgG (1:500/1:1000) & $\begin{array}{l}\text { ABC/Alexa Fluor 488-conjugated } \\
\text { streptavidin (1:500) }\end{array}$ \\
\hline GFP & $\begin{array}{l}\text { Chicken polyclonal (1:2000; catalog \#A10262, } \\
\text { Life Technologies; RRID:AB_2534023) }\end{array}$ & $\begin{array}{l}\text { Alexa Fluor 488-conjugated goat lgG }(1: 1000) \\
\text { overnight incubation }\end{array}$ & None \\
\hline VGAT & $\begin{array}{l}\text { Rabbit polyclonal (1:2000; catalog \#131003， } \\
\text { Synaptic Systems; RRID:AB_887869) }\end{array}$ & Alexa Fluor 647-conjugated goat lgG & None \\
\hline vGLUT1 & $\begin{array}{l}\text { Guinea pig polyclonal (1:1000; catalog \#135304l, } \\
\text { Synaptic Systems; RRID:AB_887878) }\end{array}$ & Cy3-conjugated goat lgG & None \\
\hline
\end{tabular}

$\mathrm{ABC}$, avidin-biotin complex.

yellow fluorescent protein (eYFP). We injected an AAV vector that encoded ChR2 [AAV2.5.hSyn.hChR2(H134R)eYFP.WPRE.hGH; 1.3e13 GC/ml titer; catalog \#26973, Addgene; Penn Vector Core] into the mPFC (AP, $2.8 \mathrm{~mm}$; ML, $0.6 \mathrm{~mm}$; DV, 4.4 and $5.0 \mathrm{~mm}$ from bregma) by means of a MicroSyringe Pump Controller system (World Precision Instruments). To cover both regions of interest, we first injected 50-50 nl/cc virus into the IL and PrL. Five weeks after injections, rats were perfused under deep anesthesia, and brains were processed for confocal microscopy as described above. The extension of virus expression in the mPFC was investigated in serial sections covering the entire area. The rostrocaudal distance between the analyzed sections was $90 \mu \mathrm{m}$. The fluorescence of eYFP was amplified with anti-GFP labeling. For coexpression analysis of eYFP and vesicular GABA transporter (vGAT)/vesicular glutamate transporter 1 (vGLUT1) in the hypothalamus, high-resolution $(0.1 \mu \mathrm{m} /$ pixel $) z$-stack images ( $z$-step size, $0.5 \mu \mathrm{m})$ were taken from 10 $\mu \mathrm{m}$ of the slice. Confocal images were acquired using identical pinhole size, gain level, axial section $(z)$ depth, and laser intensity settings for all hypothalamic slices. NIS Elements Software was used to quantify eYFP/ vGLUT1 and eYFP/vGAT double-labeled axon varicosities in the LH and MBH. A $210 \mu \mathrm{m} \times 210 \mu \mathrm{m}$ counting frame was used in both regions on three slices (at $-1.80,-1.88$, and -2.12 from bregma). The antibodies used in the experiment are presented in Table 1.

In vitro electrophysiology (Experiment 3). This study aimed at verifying whether the photostimulation of mPFC axon terminals at the level of hypothalamus can reliably affect postsynaptic neuronal activity in this area. The above-mentioned virus construct was injected into the mPFC of young male rats on postnatal day 30 (P30) to P35 under deep anesthesia, using the same protocol as described above, except that they were not submitted to behavioral testing. Animals were given 4 weeks to recover and express ChR2 in axon terminals before recording. The brain was removed rapidly and immersed in ice-cold sodium-free solution (in mM: saccharose 205.0, $\mathrm{KCl} 2.5, \mathrm{NaHCO}_{3} 26.0, \mathrm{CaCl}_{2} 1.0, \mathrm{MgCl}_{2}$ 5.0, $\mathrm{NaH}_{2} \mathrm{PO}_{4}$ 1.25 , and glucose 10 ) bubbled with a mixture of $95 \% \mathrm{O}_{2}$ and $5 \% \mathrm{CO}_{2}$. Acute $250-\mu \mathrm{m}$-thick coronal slices containing $\mathrm{MBH}$ were then prepared with a VT-1000S Vibratome (Leica) in the sodium-free solution. The slices were transferred into artificial CSF (aCSF; in mM: $\mathrm{NaCl} 130.0, \mathrm{KCl}$ 3.5, $\mathrm{NaHCO}_{3}$ 26.0, $\mathrm{CaCl}_{2} 2.5, \mathrm{MgSO}_{4}$ 1.2, $\mathrm{NaH}_{2} \mathrm{PO}_{4}$ 1.25, and glucose 10) saturated with $\mathrm{O}_{2} / \mathrm{CO}_{2}$, and kept in it for $1 \mathrm{~h}$ to equilibrate. The initial temperature of aCSF was $33^{\circ} \mathrm{C}$, which was left to cool to room temperature during equilibration. Electrophysiological recording, during which the brain slices were oxygenated by bubbling the aCSF with $\mathrm{O}_{2} / \mathrm{CO}_{2}$ gas, was performed at $33^{\circ} \mathrm{C}$. An Axopatch $200 \mathrm{~B}$ patch-clamp amplifier, a Digidata-1322A Data Acquisition System, and pCLAMP version 10.4 software (Molecular Devices; RRID:SCR_011323) were used for recording. Cells were visualized with a BX51WI IR-DIC Microscope (Olympus) located on a S'Table antivibration table (Supertech). The patch electrodes (outer diameter, $1.5 \mathrm{~mm}$, thin wall; Hilgenberg) were pulled with a Flaming-Brown P-97 puller (Sutter Instrument) and polished with an MF-830 Microforge (Narishige). MBH was identified under microscopic control. Exit of the glass fiber of the $473 \mathrm{~nm}$ emission wavelength IKE473-100-OP Laser (Ikecool) was set onto the surface of the brain slice, at the hypothalamic attack area of the $\mathrm{MBH}$. Then a neuron was patch clamped in the close vicinity (in $200-300 \mu \mathrm{m}$ ) of the end of the glass fiber. Whole-cell patch-clamp measurements were performed to record postsynaptic currents (PSCs). The neurons were voltage clamped at a pipette holding potential of $-70 \mathrm{mV}$. Pipette resistance was $1-2 \mathrm{M} \Omega$, and resistance of the gigaseal was $2-3 \mathrm{G} \Omega$. The pipette solution contained the following (in mM): K-gluconate $130, \mathrm{NaCl} 10, \mathrm{KCl} 10, \mathrm{MgCl}_{2} 0.1$, HEPES 10, EGTA 1, Mg-ATP 4, and Na-GTP 0.3 (pH 7.3 with KOH). Osmolarity was adjusted to 295-300 mOsm with sorbitol. Duration of a laser pulse was $10 \mathrm{~ms}$ with $2.5 \mathrm{~mW}$ power. A train of laser pulses was applied at $0.2 \mathrm{~Hz}$ ( 60 pulses totally). For analysis, records of the 60 pulses were averaged. In total, analysis contained 12 recorded cells from three animals. Recordings were stored and analyzed off-line using the Clampfit module of the PClamp version 10.4 software (Molecular Devices; RRID:SCR_011323).

Behavioral effects of axonal photostimulation in the $\mathrm{MBH}$ and $\mathrm{LH}$ (Experiments 4 and 5). Here we investigated the behavioral effects of axonal photostimulation in the $\mathrm{MBH}$ and $\mathrm{LH}$, respectively. The two experiments were highly similar except for the target of the stimulation (Experiment 4, MBH; Experiment 5, LH). Viral infection of the mPFC was performed as described for Experiment 2. Two weeks later, rats were implanted with an optic fiber (diameter, $250 \mu \mathrm{m}$; flat tip) either in the MBH (AP, $1.8 \mathrm{~mm}$; ML, $-1 \mathrm{~mm}$; DV, $-8.8 \mathrm{~mm}$ ) or LH (AP, $2.3 \mathrm{~mm}$; ML, $2 \mathrm{~mm}$; DV, $7.4 \mathrm{~mm}$ ). We used custom optic fibers (AFS 105/125Y; numerical aperture, 0.22 ; low $\mathrm{OH}$ ) that were obtained from Thorlabs; light transmission through the optic fiber was checked for each rat. Implants were secured to the skull by screws and acrylic resin (Duracryl Plus, SpofaDental). Behavioral testing started 2 weeks after optic fiber implantation. Virus injection sites and optic fiber locations were verified using immunohistochemistry as described above. No rat was excluded from the study except for those where virus expression extended beyond the $\mathrm{mPFC}$ or where the tip of the optic fiber was outside the target hypothalamic areas ( $n=8$ in the case of $\mathrm{MBH} ; n=10$ in the case of LH).

Territorial aggressive behavior was studied in the RI test performed in Plexiglas cages measuring $40 \times 25 \times 25 \mathrm{~cm}$. Three days before the RI test, resident animals were transferred into test cages designed for photostimulation. The 10-min-long resident/intruder test started with the placement of a smaller conspecific (300-350 g) into the test cage. Concomitantly, photostimulation was initiated and maintained for $3 \mathrm{~min}$ (473 nm light delivery, $20 \mathrm{~mW}$ output power, $20 \mathrm{~Hz}$ with $10 \mathrm{~ms}$ pulses). The same rats underwent the test four times in $2 \mathrm{~d}$ intervals. Photostimulation was applied in two of the trials. In the other two trials, rats were connected to optic fibers, but no light was delivered. Stimulation and no-stimulation trials followed according to a randomized crossover design. The test was performed in the early phase of the dark period under dim red illumination provided by two $40 \mathrm{~W}$ red bulbs placed on the ceiling of the experimental room. Behavior was video recorded, and bit- 
ing attacks were later analyzed in detail by an experimenter who was blind to treatment conditions.

Behavioral analysis focused on the patterns of biting attacks, namely on attack targeting and the relationship between offensive threats and attacks (Tóth et al., 2008). Attack episodes were analyzed at low speed (frame-by-frame if necessary) for identifying attack targets and the context of attack. An attack was considered vulnerable if it targeted the head (areas anterior to the ears), the throat (the ventral area below the ears), the belly (ventral areas between legs), or the paws. Dorsal and lateral areas (posterior to the ears and dorsal to the legs) were considered nonvulnerable targets. An attack was considered not signaled if it was not preceded by an offensive threat, and signaled if it was performed in the context of an offensive threat. Both vulnerable and nonsignaled attacks, respectively, were expressed as the percentage of total attacks according to the following formulas: vulnerable attack counts/total attack counts $\times 100$; and not signaled attack counts/total attack counts $\times 100$. The frequency and duration of the following behavioral variables were also assessed: exploration (sniffing directed toward the environment); social investigation (sniffing directed toward the opponent's flank, nasal, or anogenital region); grooming (self-grooming with forepaws and scratching with hindlegs); offense (aggressive grooming, lateral threat, offensive upright posture, mounting, and chasing taken together); defense (defensive upright, defensive kick, fleeing, and freezing taken together); dominant posture (keeping down the opponent while he is laying on his back); and submissive posture (laying on back while being kept down by the opponent).

Stimulation without ChR2 substrate (Experiment 6). This study aimed at investigating the ChR2 specificity of behavioral changes induced by photostimulation. All experimental conditions were the same, and rats were prepared as described for Experiments 4 and 5, with the exception that the virus vector did not contain the gene for ChR2. We used the adeno-associated virus vector AAV-hSyn-EYFP (titer, $3 \times 10^{12}$; Addgene; University of North Carolina, Chapel Hill, NC).

Checking the backward propagation of excitation (Experiment 7). The experiment was performed to check possible confounds resulting from the backward propagation of hypothalamic excitation into the mPFC. Rats were prepared as described for Experiments 4 and 5, and were stimulated in their home cage under resting conditions. The stimulation protocol was the one described above. Stimulation was followed by transcardial perfusion for c-Fos immunohistochemistry (see above and Table 1). c-Fos-positive cell numbers were counted in mPFC to measure potential retrograde propagation-induced neuronal activation.

The sociability test (Experiment 8 ). This experiment was performed to verify whether the effects on aggression were explained by changes in sociability. Rats used in Experiment 4 were submitted to a modified three-chamber sociability test $2 \mathrm{~d}$ after the last resident/intruder test. Subjects were placed in an open field arena measuring $100 \times 100 \times 40$ $\mathrm{cm}$. After a 5-min-long habituation period, when animals could explore the arena freely, a smaller male conspecific (age, 8-9 weeks; weight, $300-350 \mathrm{~g}$ ) was presented in a plastic perforated cylinder in the corner of the arena, whereas an empty cylinder was placed in another corner. Immediately after placing the cylinders, the photostimulation protocol described for the resident/intruder tests was initiated. We recorded the total distance covered by means of Noldus EthoVision software (locomotor activity) and the time spent with investigating cylinders by means of an H77 event-recorder software. Social motivation was evaluated by means of the following formula: $100 \times$ the time spent investigating conspecific cylinder/(time investigating conspecific cylinder + time investigating empty cylinder).

\section{Statistics}

Data were expressed as the mean \pm SEM and were analyzed by one-factor or two-factor ANOVA, as shown in Results. This was followed by Duncan pairwise comparisons where appropriate. When necessary, data were square root transformed to fulfill ANOVA requirements. Significance level was set at $p<0.05$ throughout.

\section{Results}

Large and relatively distinct mPFC neuron populations innervate the $\mathrm{MBH}$ and $\mathrm{LH}$

To investigate in detail the pathways connecting the mPFC to hypothalamic attack areas, we injected the retrograde tracers $\mathrm{CTB}$ and $\mathrm{FG}$ into the $\mathrm{MBH}$ and $\mathrm{LH}$, respectively (Fig. $1 A-C ; N=$ $8)$. Findings revealed a large share of $\mathrm{mPFC}$ neurons that send projections to the relatively small hypothalamic attack areas (Fig. $1 D-F)$. The distribution of neurons projecting to the $\mathrm{MBH}$ and $\mathrm{LH}$ was different across mPFC layers (two-factor ANOVA: $F_{\text {injection site } \times \operatorname{layer}(2,18)}=4.13, p=0.03$; Fig. $\left.1 F\right)$. Dual CTB/FG retrograde tracing revealed three distinct types of projection neurons in the mPFC (Fig. 1G,H). Of the 864 neurons counted in three rats, 598 were retrogradely labeled from the LH and 168 were labeled from the $\mathrm{MBH}$, whereas 98 were labeled from both nuclei. MBH-projecting neurons were localized in layers III/V, whereas LH-projecting neurons showed prominent expression in both layers III/V and VI. In all layers, projection neurons were intermingled with other neurons (i.e., those that did not project to the hypothalamus; Fig. $1 F$ ).

\section{The mPFC densely innervates hypothalamic centers of attack, which respond to optic stimulation}

Projection areas were investigated by injecting an AAV vector carrying the gene for ChR2 fused to eYFP into the mPFC as anterograde tracer (Fig. $2 A-D$ ). This study revealed a rich network of $\mathrm{mPFC}$ fibers in both the $\mathrm{LH}$ and $\mathrm{MBH}$ (Fig. $2 E ; N=18$ ). Coexpression of eYFP with vGLUT1 and vGAT, which accumulate in axon terminals and varicosities and indicate the presence of synapses (Chaudhry et al., 1998; Fremeau et al., 2001) showed minimal mPFC GABAergic afferents in the hypothalamus, but numerous glutamatergic release sites (Fig. $2 F, G ; N=4$ ). Finally, our electrophysiological study in acute hypothalamic brain slices performed in 12 cells from three rats (Fig. $2 H$ ) showed that the photostimulation of ChR2-expressing terminals originating from the mPFC is able to generate postsynaptic responses in the hypothalamus (Fig. 2I). These findings demonstrate robust and relatively distinct excitatory projections from the $\mathrm{mPFC}$ to the two hypothalamic attack areas, and show that the terminals are responsive to optogenetic stimulation.

\section{Stimulation of mPFC-LH pathway selectively promotes abnormal patterns of attack}

To study the functional role of the mPFC-LH projection in aggression, we induced ChR2/eYFP expression in the mPFC by the same adeno-associated virus and implanted optic fibers with tips aiming at the LH (Fig. 3-1 available at https://doi.org/10.1523/ JNEUROSCI.3234-17.2018.f3-1; $N=10$ ). Then, we submitted rats to four resident/intruder tests associated or not associated with photostimulation according to an alternating crossover design (Fig. 3A). A $473 \mathrm{~nm}$ laser stimulation at $20 \mathrm{~Hz}$ (3 min duration; $20 \mathrm{~ms}$ pulse width) — the maximal frequency at which spike fidelity was close to $100 \%$, and which reliably affected aggression in the hypothalamus (Hong et al., 2014; Lee et al., 2014) — did not affect the bite counts or the latency of bite delivery (Fig. $3 B, C$ ). However, the vast majority of bites either targeted vulnerable body parts of opponents or were not signaled socially in stimulation trials (two-factor ANOVA: $F_{\text {stimulation }(1,35)}=19.27, p=0.01$; $F_{\text {trial }(1,35)}=0.07, p=0.78 ; F_{\text {interaction }(1,35)}=0.72 ; p=0.39$; Fig. $3 D)$. Such attacks are considered abnormal in the context of regularly performed resident/intruder tests but are frequently observed in models of abnormal aggression (Haller and Kruk, 2006; 


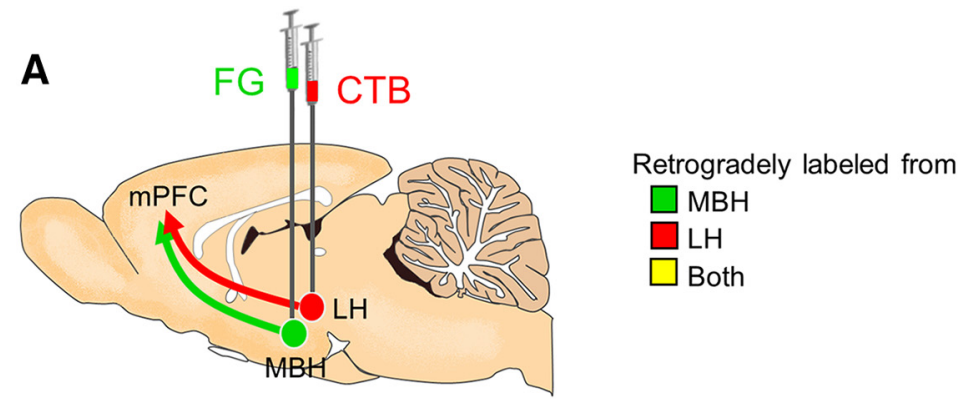

B

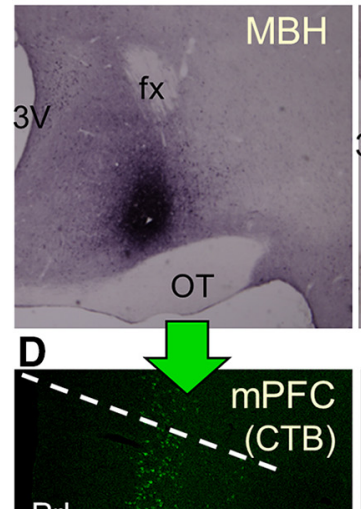

PrL

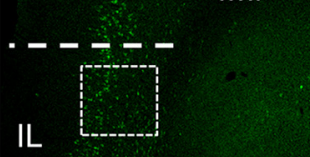

IL

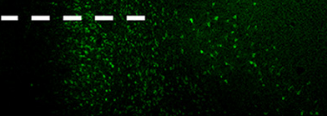

C
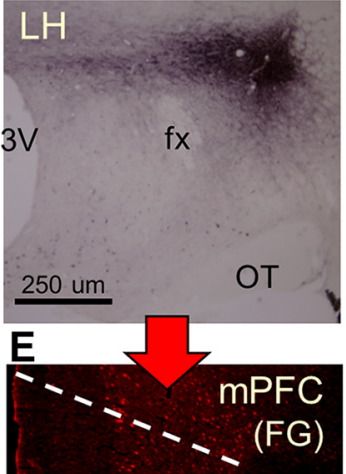

G

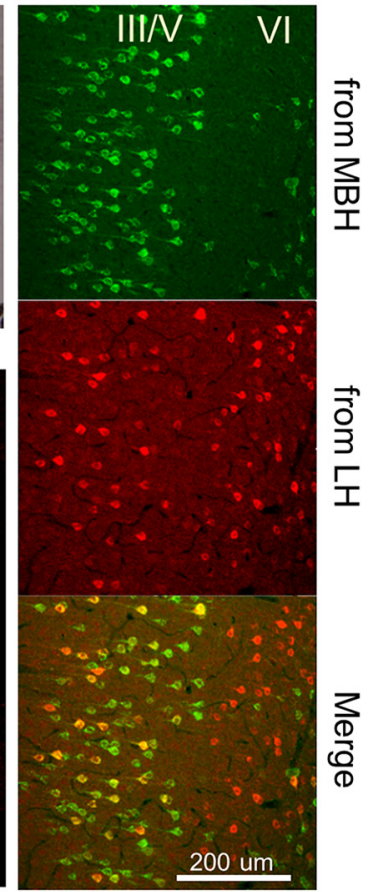

$\mathbf{F}$
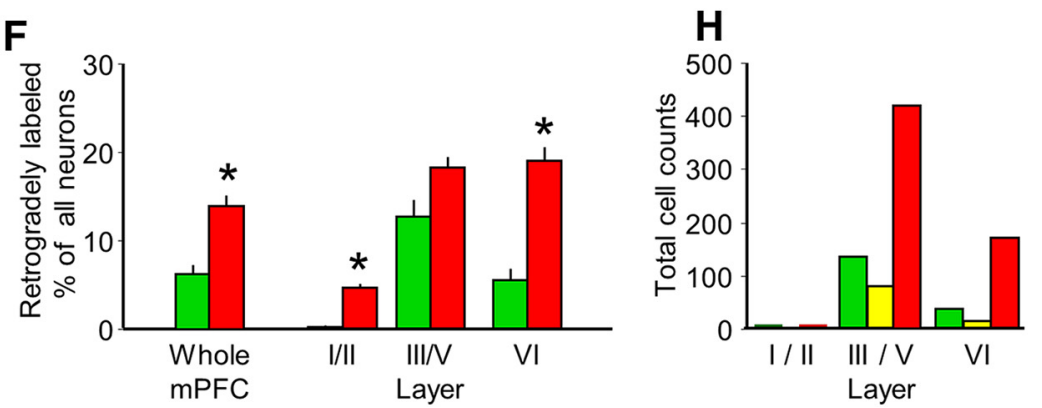

Figure 1. Retrograde labeling from $\mathrm{MBH}$ and $\mathrm{LH}$ reveals large, dominantly nonoverlapping populations of $\mathrm{mPFC}$ projection neurons. $\boldsymbol{A}$, The schematic of the study. $\boldsymbol{B}, \boldsymbol{C}$, Representative CTB and FG injection sites in the MBH and $\mathrm{LH}$, respectively. $\boldsymbol{D}, \boldsymbol{E}$, Low-magnification photomicrographs depicting CTB- and FG-labeled neurons that project to the $\mathrm{MBH}$ and $\mathrm{LH}$, respectively. $\boldsymbol{F}$, The share of projection neurons expressed as the percentage of the total number of neurons in the PrL and IL. The total number of neurons was assessed by NeuN staining (data not shown in the photomicrographs). G, Large-magnification photomicrographs illustrating $\mathrm{mPFC}$ neurons retrogradely labeled from the $\mathrm{MBH}$, the $\mathrm{LH}$, or both (coexpression). $\boldsymbol{H}$, The number of neurons expressing CTB, FG, or both of the 864 that were evaluated. Note that $\boldsymbol{F}$ shows a share of labeled neurons, whereas $\boldsymbol{H}$ shows their actual numbers. Apparent discrepancies are due to layer differences in neuron density. 3V, Third ventricle; fmi, forceps minor; fx, fornix; 0T, optic tract. * Significant difference between MBH and LH projections $(p<0.01)$.

Tulogdi et al., 2010; Miczek et al., 2013). Moreover, we saw the emergence of highly abnormal bites (i.e., bites that were not signaled socially and, in addition, targeted vulnerable body parts of opponents; , two-factor ANOVA: $F_{\text {stimulation }(1,35)}=4.37, p=0.04$; $F_{\text {trial }(1,35)}=0.01, p=0.98 ; F_{\text {interaction }(1,35)}=0.01, p=0.98$; Fig. $3 E)$. Such highly abnormal attacks occurred only in conjunction with $\mathrm{LH}$ stimulation as no similar bites were present when the $\mathrm{MBH}$ was stimulated (Fig. 4E). Stimulation affected no other behavior in the resident/intruder test (Fig. 3F), demonstrating the high behavioral specificity of the effects. To investigate the temporal relation between stimulation and effect, we compiled a graph showing both the temporal distribution of bites over the trial for each animal, and the overall frequency-distribution curve for all bites (Fig. 3G). The temporal distribution of biting attacks followed the typical inverted U-shaped curve in both types of trials, but contexttypical bites were replaced by abnormal bites over the whole trial. Noteworthy, however, effects did not carry over to the next trial (Fig. $3 H$ ).

\section{Stimulation of mPFC-MBH pathway selectively increases bite counts}

The study aimed at investigating the functional role of the $\mathrm{MPFC}-\mathrm{MBH}$ projection was performed in a highly similar fashion except that photostimulation was aimed at the $\mathrm{MBH}$ this time (Fig. $4 A$ and Fig. 4-1 available at https://doi.org/10.1523/ JNEUROSCI.3234-17.2018.f4-1; $N=8$ ). Rats delivered significantly more bites in stimulation compared with nonstimulation trials $\left(F_{\text {stimulation }(1,28)}=10.23 ; p=0.01\right.$; $F_{\text {trial }(1,28)}=0.63, p=0.43 ; F_{\text {interaction }(1,28)}=$ $0.63 ; p=0.43$; Fig. $4 B)$. This effect was also highly selective, as bite latencies, the shares of abnormal and highly abnormal attacks, as well as behaviors regularly performed in resident/intruder tests were all unresponsive to stimulation (Fig. $4 C-F$ ). A within-trial analysis of events showed that the frequency distribution of bites was markedly changed by stimulation (Fig. $4 G$ ). The increasing phase of bite delivery was similar in the two trial types, but rats did not diminish biting behavior over time when $\mathrm{mPFC}$ afferents were photostimulated in the $\mathrm{MBH}$. Again, effects did not carry over to the next trial (Fig. $4 H$ ).

\section{The specificity of effects}

To exclude that the behavioral effects of photostimulation were due to the physical effects of light rather than to the stimulation of hypothalamic mPFC afferents, we performed a study similar to the previous ones except that the virus carried the light-insensitive eYFP gene alone (Fig. $5 A$ ). Under these conditions, photostimulation of the $\mathrm{MBH}$ did not affect behavior in the resident/intruder test (Fig. 5B-F). Furthermore, we investigated whether axonal discharges elicited by photostimulation propagate backward, thus affecting the mPFC in addition to the $\mathrm{MBH}$ and $\mathrm{LH}$. The viral vector carried either eYFP alone or together with ChR2 in these studies, whereas light 

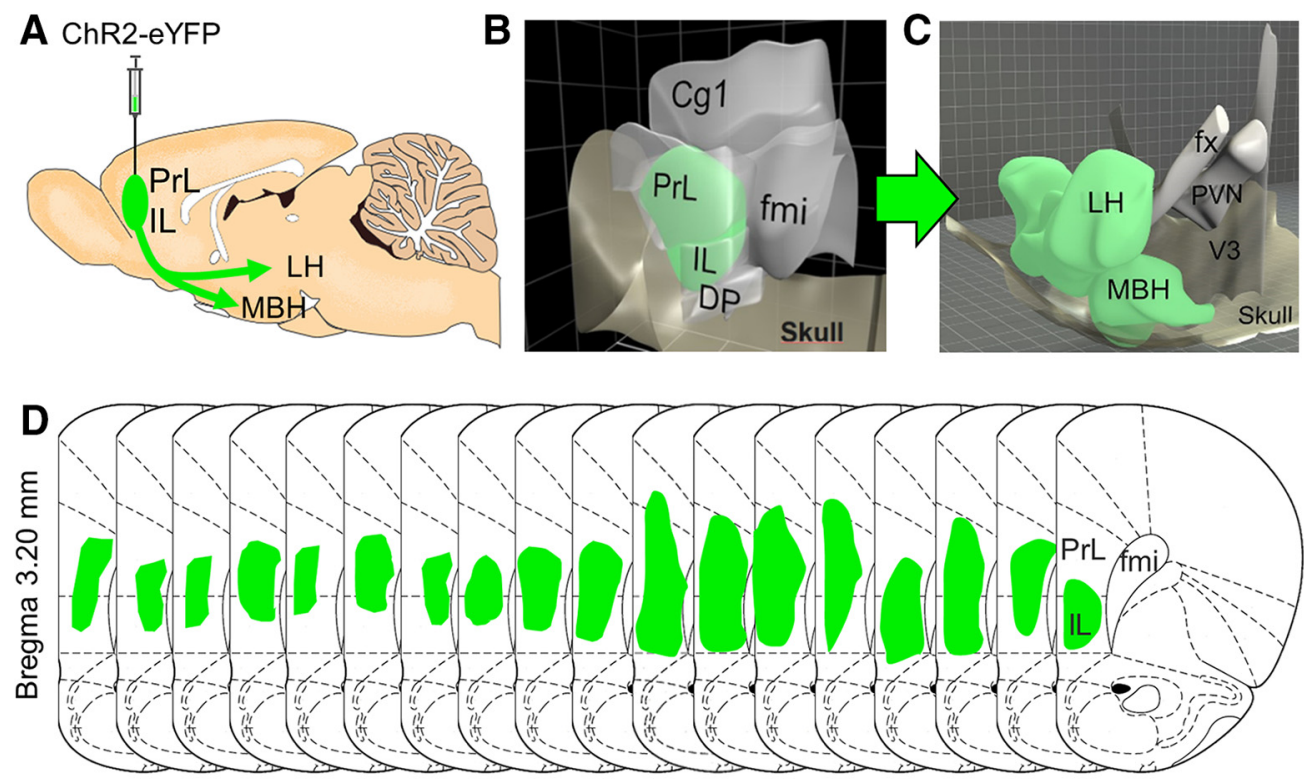

E

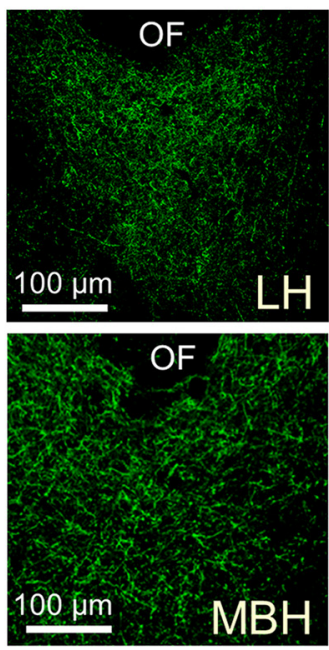

H

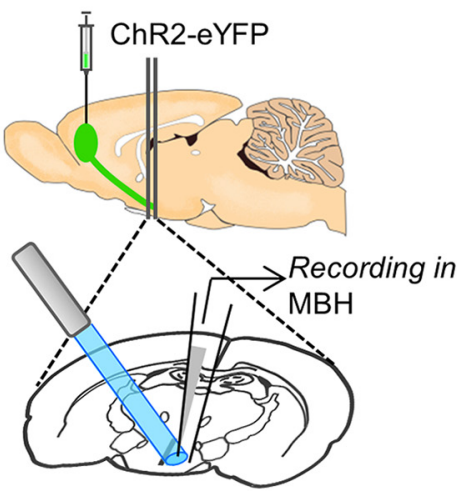

$\mathbf{F}$
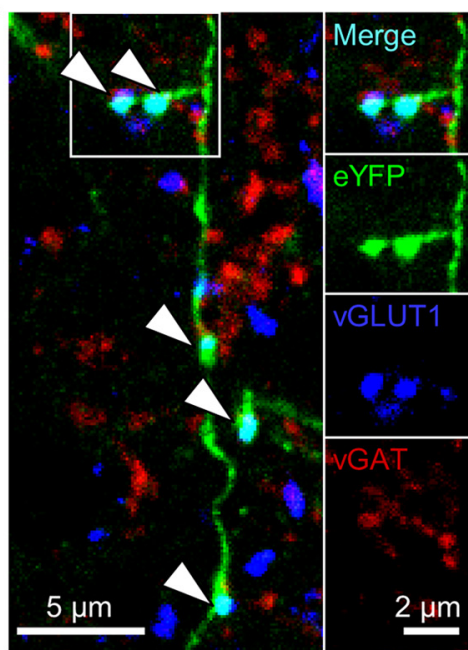

G

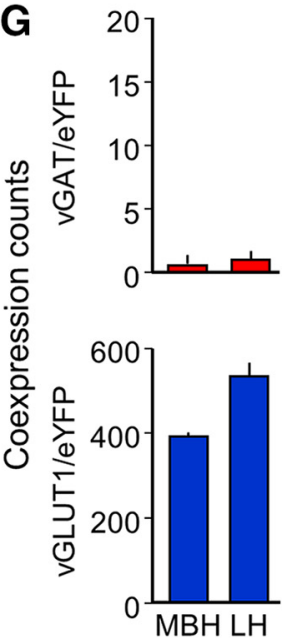

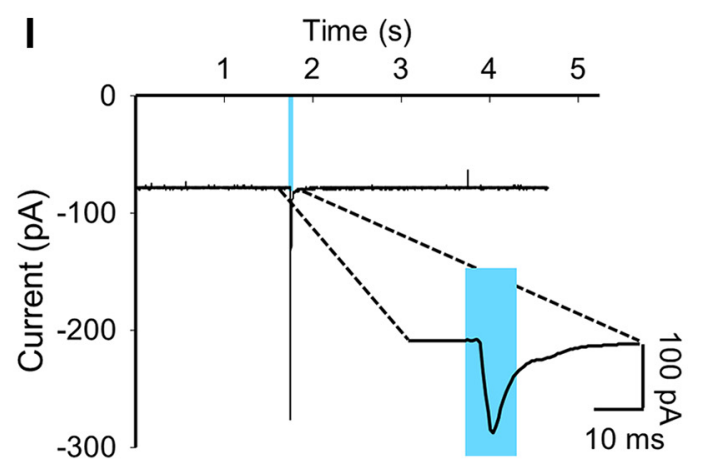

Figure 2. The mPFC densely innervates hypothalamic centers of attack by excitatory projections. $\boldsymbol{A}$, The schematic of the study. $\boldsymbol{B}$, Representative $3 \mathrm{D}$ reconstruction of eYFP labeling in the mPFC of one rat. C, 3 D reconstruction of the $L H$ and $M B H$ within the hypothalamus with anatomical landmarks. $D$, The distribution of virus infection indicated by eYFP labeling in the $\mathrm{mPFC}$ of all the 18 rats investigated in resident/intruder tests. The schematics show brain sections at $3.2 \mathrm{~mm}$ from bregma, where labeling was most extensive. $\boldsymbol{E}$, Confocal photomicrographs illustrating the density of prefrontal fibers in the LH and MBH. $F$, Confocal photomicrographs illustrating prefrontal terminals triple labeled for eYFP, vGAT, and vGLUT1. G, The average number of terminals coexpressing VGAT/eYFP and vGLUT1/eYFP in the LH and MBH. $\boldsymbol{H}$, The schematic of in vitro electrophysiological recordings. I, Averaged PSCs evoked by photostimulation in hypothalamic neurons adjacent to eYFP-labeled terminals. Insert, Zoomed version of I showing the temporal relationship between the laser shot and the evoked PSC. Cg1, Anterior cingulate cortex; DP, dorsal peduncular cortex; fmi, forceps minor; $\mathrm{fx}$, fornix; $\mathrm{OF}$, the tip of the optic fiber; $\mathrm{PVN}$, paraventricular nucleus of the hypothalamus; $\mathrm{V} 3$, third ventricle. 

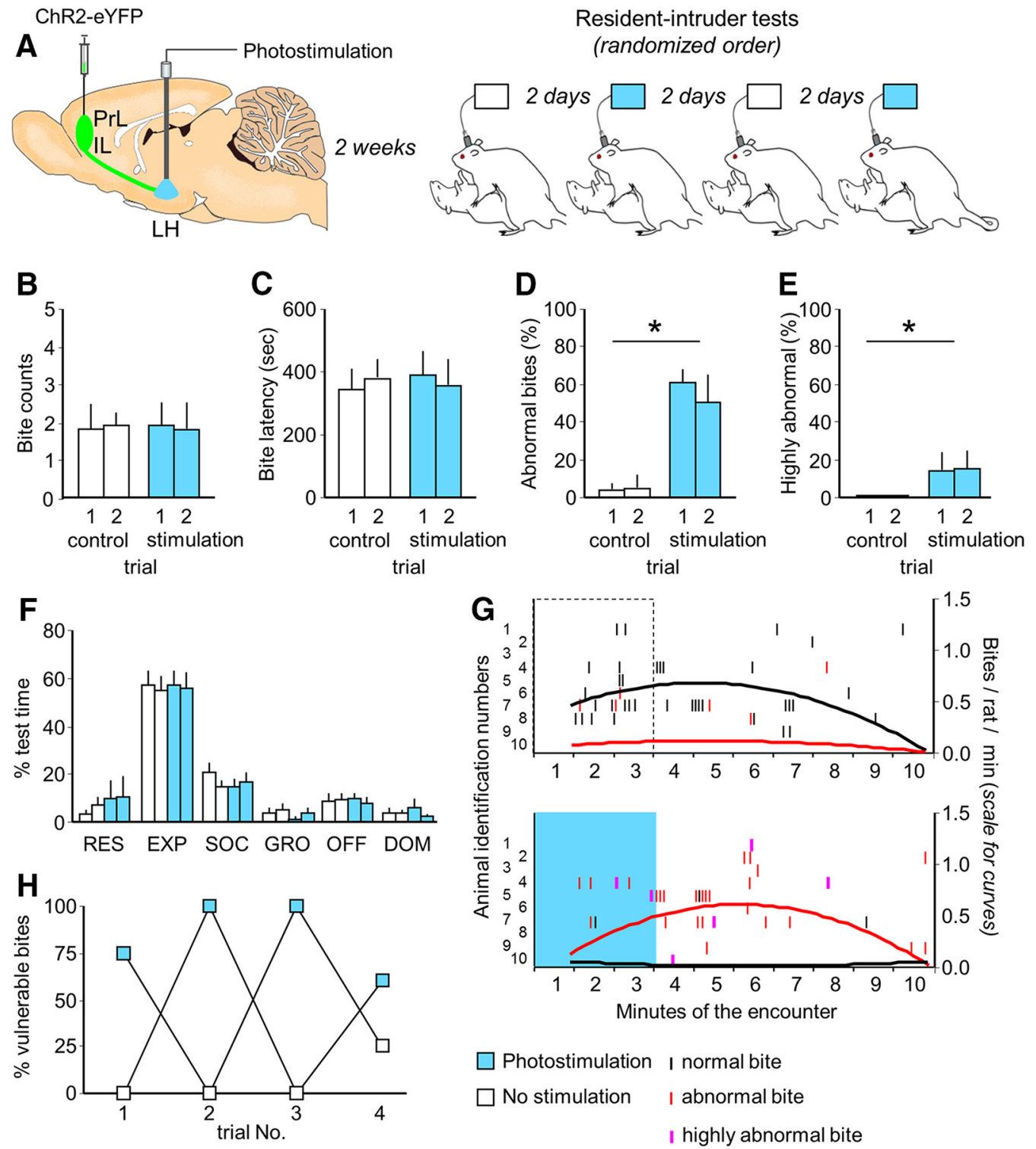

\section{Photostimulation I normal bite \\ No stimulation I abnormal bite \\ I highly abnormal bite}

Figure 3. Photostimulation of mPFC afferents in the LH selectively increased the share of abnormal attacks. $\boldsymbol{A}$, The schematic of the study. $\boldsymbol{B}-\boldsymbol{E}$, Variables that characterize biting attacks (for explanations, see legends below). $\boldsymbol{F}$, Behaviors recorded during resident/intruder tests. Trials were shown here as contiguous columns. $\mathbf{G}$, The temporal distribution of biting attacks. The presence of stimulation was indicated by the color code. Each row of vertical lines depicts bites delivered by individual rats; distance from the left-hand $y$-axis shows their timing. Curves are second-order polynomial fits of total bite frequencies over the encounter (see right-hand $y$-axis for the scale). $\boldsymbol{H}$, Changes in the share of vulnerable bites over trials in two representative rats in which stimulation was associated with the first and third or the second and fourth trials, respectively. Please see Figure 3-1 available at https://doi.org/10.1523/JNEUROSCI.3234-17.2018.f3-1 for the location of the tips of optic fibers within the LH. Abnormal attacks, Bites not preceded by social signals or aimed at vulnerable targets (e.g., the head, throat or belly); DOM, dominant posture; EXP, exploration; GRO, grooming; highly abnormal: bites targeting vulnerable body parts of opponents without social signaling; OFF, offensive behaviors; RES, resting; SOC, social interactions. *Significant difference between stimulated and nonstimulated R/I tests $(p<0.01)$.

was administered into the $\mathrm{LH}$ or $\mathrm{MBH}$. c-Fos expression in the mPFC was highly similar in the two groups (Fig. $5 G-I$ ). Finally, we checked whether the effects of stimulation were secondary to changes in sociability, which would have rendered them consequences of general changes in social motivation rather than real behavioral effects. Stimulation, however, affected neither social preference nor locomotion in the sociability test (Fig. 5J-L). These findings show that behavioral effects observed in the previous studies were due to the selective activation of prefrontal-hypothalamic projections and underline the behavioral specificity of the effects.

\section{Discussion}

Here we show that the photostimulation of hypothalamic mPFC terminals elicited specific behavioral responses in the resident/ intruder test. Particularly, the photostimulation of terminals in the $\mathrm{MBH}$ selectively increased attack counts, whereas the stimulation of mPFC terminals in the LH elicited violent attacks without changing their frequency or any other behavior. This subtle mechanism appeared to involve a large share of mPFC neurons, which densely and rather selectively innervate the two hypothalamic sites where they form a large number of glutamate release sites. Together, our findings show that the overall roles of the mPFC in aggression are distributed among highly specialized prefrontal neuron populations, the hypothalamic terminals of which contain vGLUT1 (i.e., are likely glutamatergic).

The $\mathrm{mPFC}$ projects to a large variety of brain structures from neighboring cortical structures, through the midbrain, to caudal parts of the brainstem (Sesack et al., 1989; Ongür and Price, 2000; 


\section{ChR2-EYFP}

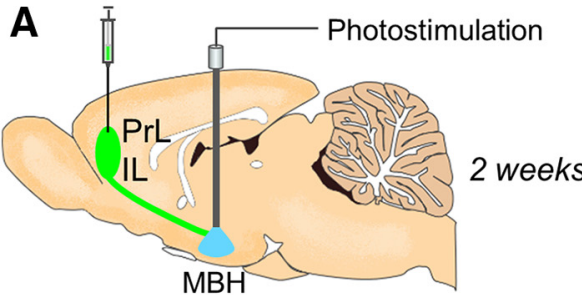

B
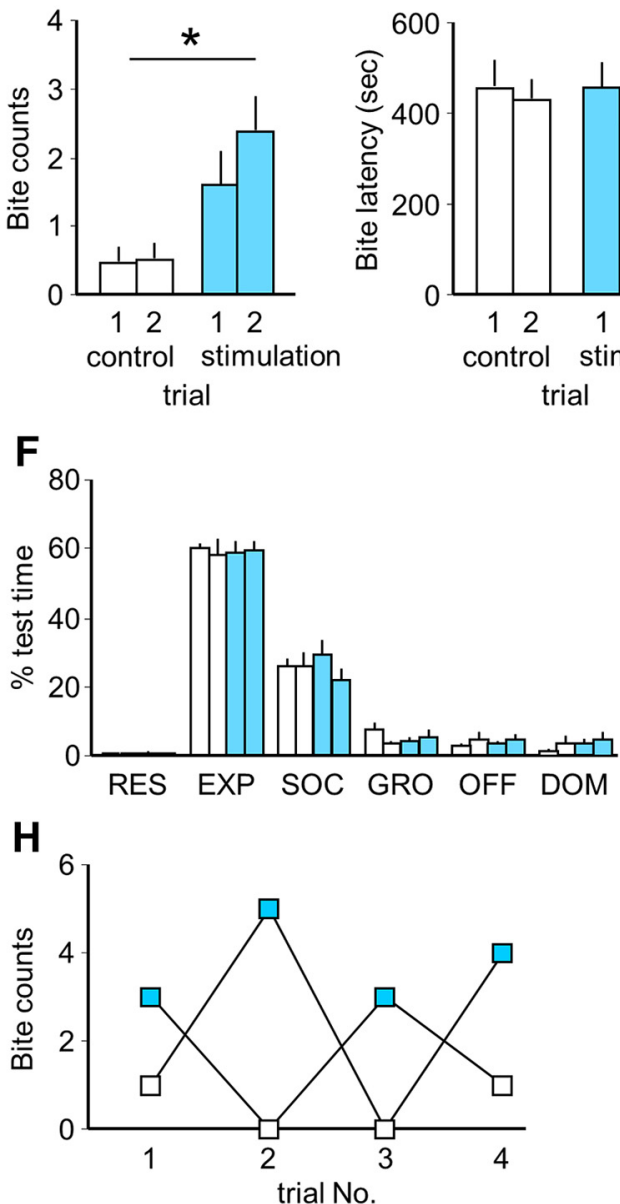

Resident-intruder tests

(randomized order)

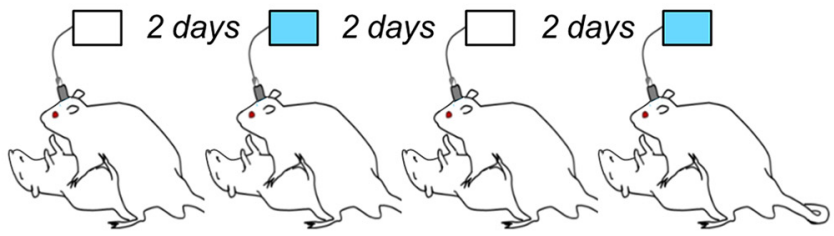

D
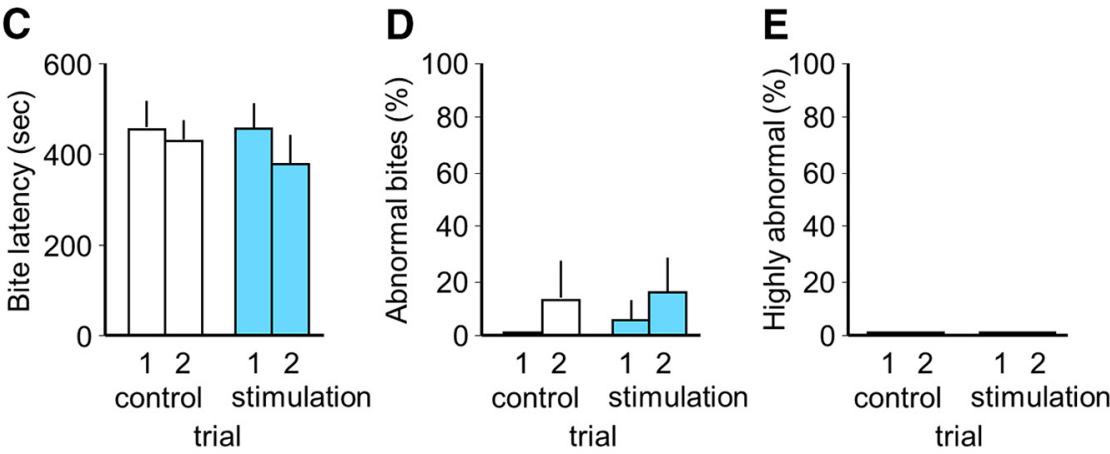

G

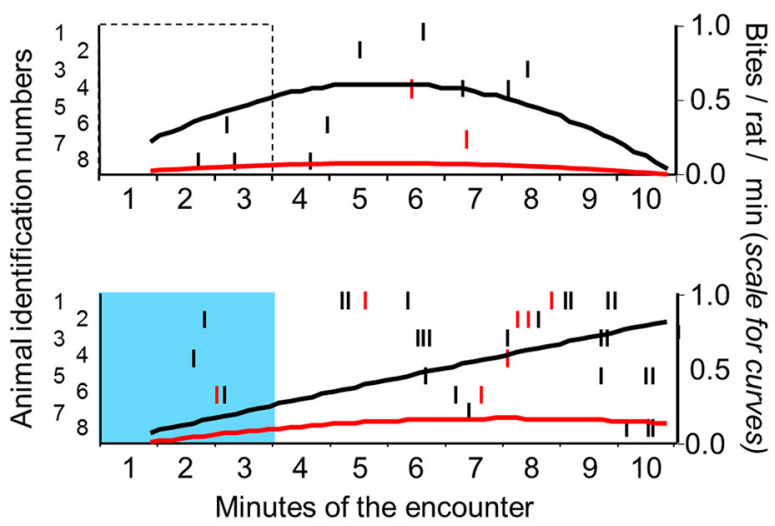

Photostimulation I normal bite

No stimulation | abnormal bite

Figure 4. Photostimulation of mPFC afferents in the MBH selectively increased attack counts. $\boldsymbol{A}$, The schematic of the study. $\boldsymbol{B}-\boldsymbol{E}$, Variables that characterize biting attacks. $\boldsymbol{F}$, Behaviors recorded during resident/intruder tests. Subsequent trials were shown here as contiguous columns. $\mathbf{G}$, The temporal distribution of biting attacks. $\boldsymbol{H}$, Changes in bite counts over trials in two representative rats in which stimulation was associated with the first and third or the second and fourth trials, respectively. Please see Figure 4-1 available at https://doi.org/10.1523/JNEUROSCI.3234-17.2018.f4-1 for the location of the tips of optic fibers within the MBH. For explanations and abbreviations, see Figure 3 . * Significant difference between stimulated and non-stimulated R/I tests ( $p<0.01$ ).

Heidbreder and Groenewegen, 2003). Considering the large number of $\mathrm{mPFC}$ target areas, the high share of neurons projecting to aggression-related hypothalamic sites, together with their rich arborization suggested per se that the $\mathrm{MPFC}$ has important roles in the control of aggression. Importantly, mPFC neurons proved to be rather specific with respect to their hypothalamic targets, suggesting the existence of neuron populations dedicated to particular brain loci.

The stimulation of important aspects of aggression by projections of the mPFC appears highly surprising, as the prefrontal deficit theory of aggression predicts the opposite, with one of the main arguments being that structural prefrontal deficits decrease aggression (Glenn et al., 2013; Blair, 2015). It is noteworthy that this hypothesis was based on studies that considered the area as a whole and did not dissect the functions of particular projections. Even in such studies, however, aggression-induced brain activation patterns support the notion that the mPFC may promote aggression acutely, namely during its execution. This line of evidence shows that aggression increases the activity of the prefrontal cortex in both animals and humans; moreover, activation was further increased in aggression-related psychopathologies and rodent models of abnormal aggression (Halász et al., 2006; Haller et al., 2006; Lotze et al., 2007; New et al., 2009; Veit et al., 2010; Beiderbeck et al., 2012; Montag et al., 2012; Toth et al., 2012; Ago et al., 2013). We showed that the two apparently contradictory phenomena can coexist: rats submitted to the postweaning social isolation model of abnormal aggression showed both predispositional structural deficits in the $\mathrm{mPFC}$ (including volume reduc- 
A eYFP

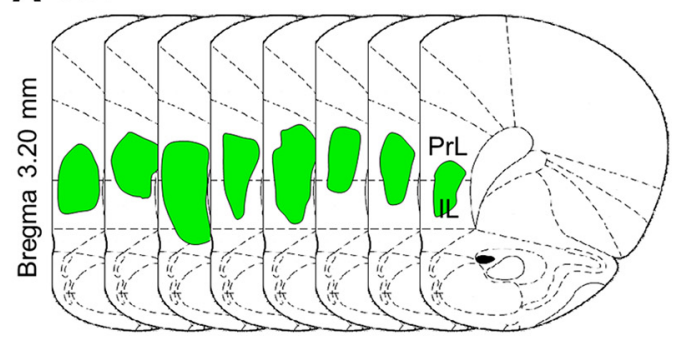

D

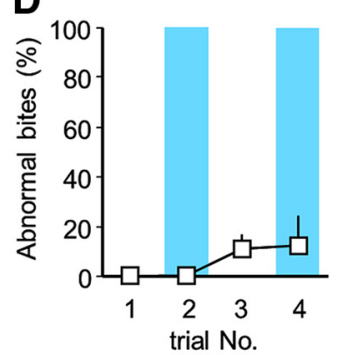

G

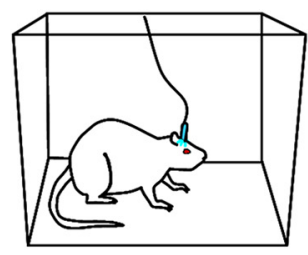

J
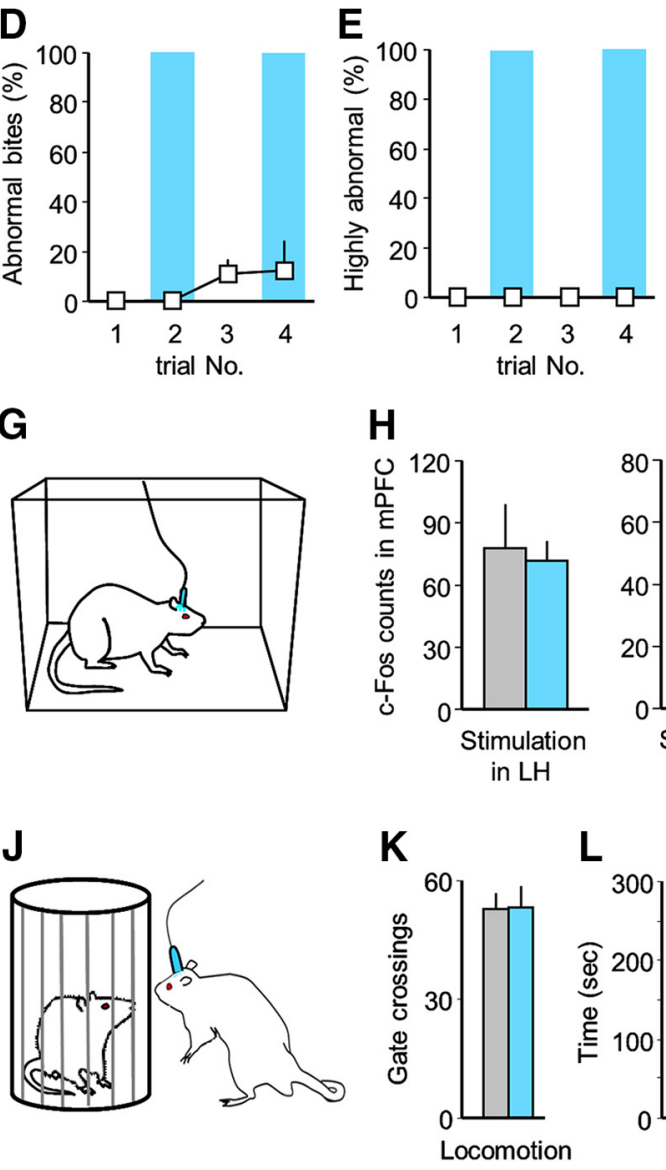

B

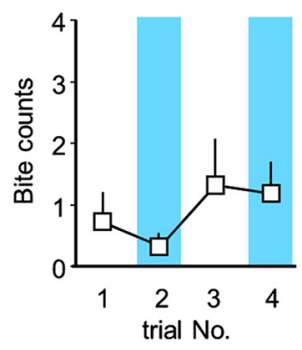

C

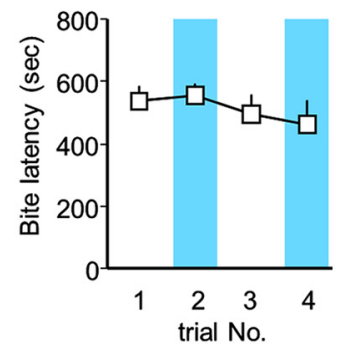

F
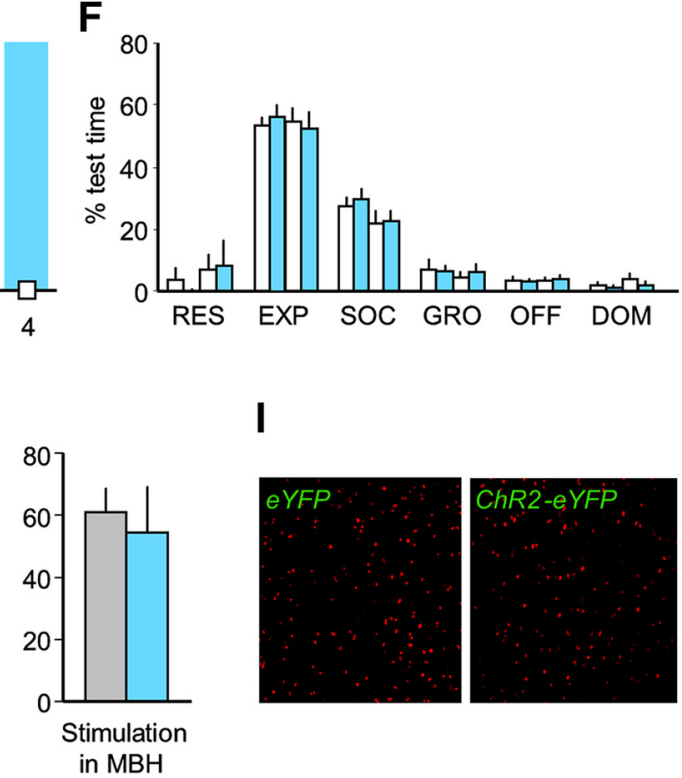

I

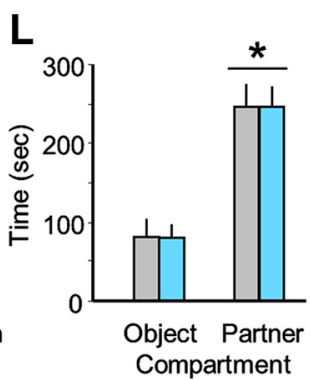

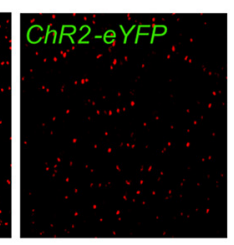

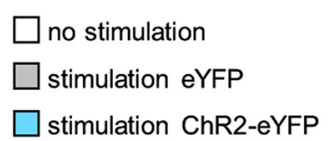

Figure 5. Control studies. $\boldsymbol{A}$, The extension of virus infection in rats studied in the resident/intruder test presented here. The experiment was performed according to the schematic shown in Figure 3, but the virus carried this time the gene of the light-insensitive eYFP alone. $\boldsymbol{B}-\boldsymbol{F}$, Behaviors recorded in the four resident/intruder trials. $\boldsymbol{G}$, Rats treated as shown in Figure $3 \boldsymbol{A}$ were photostimulated in their home cage, after which their brains were sampled and assessed for the expression of the neuronal activation marker c-Fos in the mPFC. $\boldsymbol{H}, \boldsymbol{I}$, The findings and representative photomicrographs of the c-Fos expression study. $\boldsymbol{J}$, Rats treated as shown in Figure $3 A$ were photostimulated in the MBH and submitted to the three-chamber sociability test. $\boldsymbol{K}$, $\boldsymbol{L}$, The results of the three-chamber sociability test. For explanations and abbreviations, see Figure 3. *Significant difference between stimulated and nonstimulated R/I tests ( $p<0.01)$.

tions) and increased activation by aggression in the very same area (Biro et al., 2017). Present findings show that particular projections of the mPFC do increase aggression, which further supports the notion that while long-term prefrontal deficits may induce a predilection toward aggressiveness, the execution of aggressive acts requires high prefrontal activity (Haller, 2014).

In our studies, the temporal relationship between stimulation and effect was rather different from that seen earlier with the direct stimulation of the hypothalamus. In these earlier studies, behavioral responses emerged seconds after the start of electric stimulations, and vanished immediately after their halting (Vergnes and Karli, 1969; Bandler, 1970; Kruk et al., 1990). Similarly, the optogenetic stimulation of the mouse VMHvl was immediately fol- lowed by bite delivery without apparent poststimulation effects (Lin et al., 2011; Lee et al., 2014). The stimulation of mPFC terminals in the very same hypothalamic areas altered behavior after a considerable latency, and effects lasted considerably longer than the stimulation, albeit remaining reversible over the $2 \mathrm{~d}$ that separated trials. This suggests that the $\mathrm{mPFC}$ is not a direct activator of hypothalamic attack mechanisms but exerts modulatory influences. One can hypothesize that such modulatory influences on the functioning of hypothalamic attack areas may have gradually changed the valence of the conflict by making it more violent. Once this change in behavioral valence emerged, the new strategy became self-sustaining and did not require the continuation of stimulation. The mechanisms by which the hypothalamus translates glutamatergic mPFC inputs into specific action patterns re- 
mains to be elucidated; however, novel concepts about the role of the hypothalamus in aggression outline that attack centers are not "automated" executory regions but integrate a variety of sensorimotor information (Falkner and Lin, 2014). The present findings show that hypothalamic attack centers integrate this sensory information with prefrontal inputs to control particular behaviors.

It was established that the mPFC monitors ongoing conflicts, assesses and anticipates the value of different behavioral options, and decisively contributes to behavioral response selection (Vertes, 2006; Bonini et al., 2014; Saunders et al., 2017). In the case of aggression, dedicated hypothalamic projections of the $\mathrm{mPFC}$ provide the area with the capacity to control important aspects of violent behavior separately, and by this making prefrontal control more flexible and precise. In the perspective of these findings, decision-making by local prefrontal circuits (Ridderinkhof et al., 2004) may be perceived as occurring through mechanisms that compete for the activation of such highly specialized mPFC neuron populations, which provide a vehicle for the translation of decisions into aggressive acts.

\section{References}

Ago Y, Araki R, Tanaka T, Sasaga A, Nishiyama S, Takuma K, Matsuda T (2013) Role of social encounter-induced activation of prefrontal serotonergic systems in the abnormal behaviors of isolation-reared mice. Neuropsychopharmacology 38:1535-1547. CrossRef Medline

Bandler RJ Jr (1970) Cholinergic synapses in the lateral hypothalamus for the control of predatory aggression in the rat. Brain Res 20:409-424. CrossRef Medline

Beiderbeck DI, Reber SO, Havasi A, Bredewold R, Veenema AH, Neumann ID (2012) High and abnormal forms of aggression in rats with extremes in trait anxiety-involvement of the dopamine system in the nucleus accumbens. Psychoneuroendocrinology 37:1969-1980. CrossRef Medline

Biro L, Toth M, Sipos E, Bruzsik B, Tulogdi A, Bendahan S, Sandi C, Haller J (2017) Structural and functional alterations in the prefrontal cortex after post-weaning social isolation: relationship with species-typical and deviant aggression. Brain Struct Funct 222:1861-1875. CrossRef Medline

Blair RJ (2015) Psychopathic traits from an RDoC perspective. Curr Opin Neurobiol 30:79-84. CrossRef Medline

Bonini F, Burle B, Liégeois-Chauvel C, Régis J, Chauvel P, Vidal F (2014) Action monitoring and medial frontal cortex: leading role of supplementary motor area. Science 343:888-891. CrossRef Medline

Chaudhry FA, Reimer RJ, Bellocchio EE, Danbolt NC, Osen KK, Edwards RH, Storm-Mathisen J (1998) The vesicular GABA transporter, VGAT, localizes to synaptic vesicles in sets of glycinergic as well as GABAergic neurons. J Neurosci 18:9733-9750. Medline

Falkner AL, Lin D (2014) Recent advances in understanding the role of the hypothalamic circuit during aggression. Front Syst Neurosci 8:168. CrossRef Medline

Fremeau RT Jr, Troyer MD, Pahner I, Nygaard GO, Tran CH, Reimer RJ, Bellocchio EE, Fortin D, Storm-Mathisen J, Edwards RH (2001) The expression of vesicular glutamate transporters defines two classes of excitatory synapse. Neuron 31:247-260. CrossRef Medline

Glenn AL, Johnson AK, Raine A (2013) Antisocial personality disorder: a current review. Curr Psychiatry Rep 15:427. CrossRef Medline

Halász J, Tóth M, Kalló I, Liposits Z, Haller J (2006) The activation of prefrontal cortical neurons in aggression-a double labeling study. Behav Brain Res 175:166-175. CrossRef Medline

Haller J (2013) The neurobiology of abnormal manifestations of aggression-a review of hypothalamic mechanisms in cats, rodents, and humans. Brain Res Bull 93:97-109. CrossRef Medline

Haller J (2014) Neurobiological Bases of Abnormal Aggression and Violent Behaviour. Vienna, Austria: Springer.

Haller J, Kruk MR (2006) Normal and abnormal aggression: human disorders and novel laboratory models. Neurosci Biobehav Rev 30:292-303. CrossRef Medline

Haller J, van de Schraaf J, Kruk MR (2001) Deviant forms of aggression in glucocorticoid hyporeactive rats: a model for 'pathological' aggression? J Neuroendocrinol 13:102-107. CrossRef Medline
Haller J, Tóth M, Halasz J, De Boer SF (2006) Patterns of violent aggressioninduced brain c-fos expression in male mice selected for aggressiveness. Physiol Behav 88:173-182. CrossRef Medline

Heidbreder CA, Groenewegen HJ (2003) The medial prefrontal cortex in the rat: evidence for a dorso-ventral distinction based upon functional and anatomical characteristics. Neurosci Biobehav Rev 27:555-579. CrossRef Medline

Hong W, Kim DW, Anderson DJ (2014) Antagonistic control of social versus repetitive self-grooming behaviors by separable amygdala neuronal subsets. Cell 158:1348-1361. CrossRef Medline

Kruk MR, Van der Laan CE, Van der Poel AM, Van Erp AM, Meelis W (1990) Strain differences in attack patterns elicited by electrical stimulation in the hypothalamus of male CPBWEzob and CPBWI rats. Aggress Behav 16: 177-190. CrossRef

Lee H, Kim DW, Remedios R, Anthony TE, Chang A, Madisen L, Zeng H, Anderson DJ (2014) Scalable control of mounting and attack by Esr 1+ neurons in the ventromedial hypothalamus. Nature 509:627-632. CrossRef Medline

Lin D, Boyle MP, Dollar P, Lee H, Lein ES, Perona P, Anderson DJ (2011) Functional identification of an aggression locus in the mouse hypothalamus. Nature 470:221-226. CrossRef Medline

Lotze M, Veit R, Anders S, Birbaumer N (2007) Evidence for a different role of the ventral and dorsal medial prefrontal cortex for social reactive aggression: an interactive fMRI study. Neuroimage 34:470-478. CrossRef Medline

Miczek KA, de Boer SF, Haller J (2013) Excessive aggression as model of violence: a critical evaluation of current preclinical methods. Psychopharmacology 226:445-458. CrossRef Medline

Montag C, Weber B, Trautner P, Newport B, Markett S, Walter NT, Felten A, Reuter M (2012) Does excessive play of violent first-person-shootervideo-games dampen brain activity in response to emotional stimuli? Biol Psychol 89:107-111. CrossRef Medline

New AS, Hazlett EA, Newmark RE, Zhang J, Triebwasser J, Meyerson D, Lazarus S, Trisdorfer R, Goldstein KE, Goodman M, Koenigsberg HW, Flory JD, Siever LJ, Buchsbaum MS (2009) Laboratory induced aggression: a positron emission tomography study of aggressive individuals with borderline personality disorder. Biol Psychiatry 66:1107-1114. CrossRef Medline

Ongür D, Price JL (2000) The organization of networks within the orbital and medial prefrontal cortex of rats, monkeys and humans. Cereb Cortex 10:206-219. CrossRef Medline

Pessoa L (2015) Précis on the cognitive-emotional brain. Behav Brain Sci 38:e71. CrossRef Medline

Ray RD, Zald DH (2012) Anatomical insights into the interaction of emotion and cognition in the prefrontal cortex. Neurosci Biobehav Rev 36: 479-501. CrossRef Medline

Ridderinkhof KR, Ullsperger M, Crone EA, Nieuwenhuis S (2004) The role of the medial frontal cortex in cognitive control. Science 306:443-447. CrossRef Medline

Saunders B, Lin H, Milyavskaya M, Inzlicht M (2017) The emotive nature of conflict monitoring in the medial prefrontal cortex. Int J Psychophysiol 119:31-40. CrossRef Medline

Sesack SR, Deutch AY, Roth RH, Bunney BS (1989) Topographical organization of the efferent projections of the medial prefrontal cortex in the rat: an anterograde tract-tracing study with phaseolus vulgaris leucoagglutinin. J Comp Neurol 290:213-242. CrossRef Medline

Siegel A, Roeling TA, Gregg TR, Kruk MR (1999) Neuropharmacology of brain-stimulation-evoked aggression. Neurosci Biobehav Rev 23:359_ 389. CrossRef Medline

Siegel A, Bhatt S, Bhatt R, Zalcman SS (2007) The neurobiological bases for development of pharmacological treatments of aggressive disorders. Curr Neuropharmacol 5:135-147. CrossRef Medline

Smith EE, Jonides J (1999) Storage and executive processes in the frontal lobes. Science 283:1657-1661. CrossRef Medline

Tóth M, Halász J, Mikics E, Barsy B, Haller J (2008) Early social deprivation induces disturbed social communication and violent aggression in adulthood. Behav Neurosci 122:849-854. CrossRef Medline

Toth M, Fuzesi T, Halasz J, Tulogdi A, Haller J (2010) Neural inputs of the hypothalamic "aggression area" in the rat. Behav Brain Res 215:7-20. CrossRef Medline

Toth M, Tulogdi A, Biro L, Soros P, Mikics E, Haller J (2012) The neural 
background of hyper-emotional aggression induced by post-weaning social isolation. Behav Brain Res 233:120-129. CrossRef Medline

Tulogdi A, Toth M, Halasz J, Mikics E, Fuzesi T, Haller J (2010) Brain mechanisms involved in predatory aggression are activated in a laboratory model of violent intra-specific aggression. Eur J Neurosci 32:1744-1753. CrossRef Medline

Tye KM, Deisseroth K (2012) Optogenetic investigation of neural circuits underlying brain disease in animal models. Nat Rev Neurosci 13:251-266. CrossRef Medline

Van De Werd HJ, Rajkowska G, Evers P, Uylings HB (2010) Cytoarchitectonic and chemoarchitectonic characterization of the prefrontal cortical areas in the mouse. Brain Struct Funct 214:339-353. CrossRef Medline
Veit R, Lotze M, Sewing S, Missenhardt H, Gaber T, Birbaumer N (2010) Aberrant social and cerebral responding in a competitive reaction time paradigm in criminal psychopaths. Neuroimage 49:3365-3372. CrossRef Medline

Vergnes M, Karli P (1969) Interspecific rat-mice agression behavior: effects of electric stimulation of the lateral hypothalamus, amygdala and hypopocampus. J Physiol (Paris) 61 [Suppl. 2]:425. Medline

Vertes RP (2006) Interactions among the medial prefrontal cortex, hippocampus and midline thalamus in emotional and cognitive processing in the rat. Neuroscience 142:1-20. CrossRef Medline

Yizhar O, Fenno LE, Davidson TJ, Mogri M, Deisseroth K (2011) Optogenetics in neural systems. Neuron 71:9-34. CrossRef Medline 